\title{
Pictorial warning labels as deterrents of alcohol abuse
}

\author{
Luigi Piper \\ University of Bari, Bari, Italy, and \\ Antonio Mileti, M. Irene Prete and Gianluigi Guido \\ University of Salento, Lecce, Italy
}

\begin{abstract}
Purpose - The purpose of this research is to demonstrate the effectiveness of pictorial warning labels that leverage the risk of obesity as a deterrent against alcohol abuse. It evaluates the impact of three different kinds of warning labels that can potentially discourage alcoholic drinking: (1) a claim, in text format, that cautions consumers about the product (i.e. a responsibility warning statement); (2) a textual warning label, text-format information on the content of the product or the consequences of excessive consumption (i.e. a synthetic nutritional table); (3) a pictorial warning label, an image depicting a food product with a caloric content equivalent to that of an alcoholic beverage. Design/methodology/approach - In Study 1, a $2 \times 2 \times 2$ factorial design is used to evaluate the intention to buy different alcoholic cocktails. The stimuli comprised two cocktails that are similar in alcoholic volume, but different in their caloric content. The images of the products were presented across eight warning label conditions and shown to 480 randomly selected Italian respondents who quantified their intention to buy the product. In Study 2, a different sample of 34 Italian respondents was solicited with the same stimuli considered in Study 1, and neuropsychological measurements through Electroencephalography (EEG) were registered. A post hoc least significance difference (LSD) test is used to analyse data.

Findings - The results show that only the presence of an image representing an alcoholic beverage's caloric content causes a significant reduction in consumers' purchase intentions. This effect is due to the increase in negative emotions caused by pictorial warning labels.

Originality/value - The findings provide interesting insights on pictorial warning labels, which can influence the intention to purchase alcoholic beverages. They confirmed that the use of images in the warning labels has a greater impact than text, and that the risk of obesity is an effective deterrent in encouraging consumers to make healthier choices.
\end{abstract}

Keywords Alcoholic consumption, Pictorial warning labels, Textual warning labels, Claim, EEG analysis, Purchase intention

Paper type Research paper

\section{Highlights}

- Claims and textual warning labels do not seem to discourage alcoholic drinking

- New ways to limit the negative effects of excessive alcohol consumption are needed

- Nutritional information could be presented with an image or a figure

- A pictorial warning label represents the caloric intake using an equivalent product

- Pictorial warning labels decrease the intention to purchase an alcoholic beverage

- Pictorial warning labels determine an increase in negative emotions

(C) Luigi Piper, Antonio Mileti, M. Irene Prete and Gianluigi Guido. Published by Emerald Publishing Limited. This article is published under the Creative Commons Attribution (CC BY 4.0) licence. Anyone may reproduce, distribute, translate and create derivative works of this article (for both commercial and non-commercial purposes), subject to full attribution to the original publication and authors. The full terms of this licence may be seen at http://creativecommons.org/licences/by/4.0/legalcode

The authors would like to express their sincere appreciation to Dr Giorgio Trianni, Dr Laura Carmillo, and Dr Emanuela Preite of the neurology unit of "V. Fazzi" Hospital for their expertise and assistance throughout all neurological aspects of our study.

\section{Pictorial warning labels}

Received 9 March 2021

Revised 28 May 2021 10 August 2021

Accepted 30 August 2021 
BFJ

123,13

\section{Introduction}

Alcohol is defined as a regulated drug and classified as a depressant, as it inhibits reaction times, motor functions and speech (World Population Review, 2020). Worldwide, about 2.348 billion people are current drinkers. Per capita alcohol consumption has seemingly experienced slight and steady growth since $2005(+1.6 \%)$, and, according to forecasts by the World Health Organization (2018), the trend will remain steady at the global level until 2025. As a result, the harmful use of alcohol represents a huge global burden of disease that outweighs other risk factors (World Health Organization, 2018). In fact, the habitual consumption of alcohol is the source for more than 200 kinds of diseases and conditions.

Besides this, alcohol has an energy content of 7.1 kilocalories per gram, which is exceeded only by fat $(9 \mathrm{kcal} / \mathrm{g})$. For this reason, many institutions have focused on alcohol as an obesity risk factor (Battista and Leatherdale, 2017; Chakraborty, 2014; Yeomans, 2010). Even if moderate consumption does not seem to cause weight gain, excessive consumption (i.e. more than 3 drinks/ day in females and more than 4 drinks/day in males) is associated with higher risks of obesity (Kim et al., 2021; Traversy and Chaput, 2015). This effect seems to be higher for women than for men (Chakraborty, 2014; Lahti-Koski et al., 2002). Moreover, the so-called "binge drinking" phenomenon - the most common abuse of alcoholic consumption, which consists of drinking more than four (for women) or five (for men) alcoholic beverages in the span of about two hours has clear negative effects in both males and females (Chakraborty, 2014; Suter et al., 1997).

Research finds that this pattern of alcohol consumption is frequent both in the USA and Europe (Bartoli et al., 2014; Kanny et al., 2020; Kuntsche et al., 2004; Naimi et al., 2003; Plant et al., 2009), with a higher prevalence among men (Slutske, 2005). However, the behaviour is increasing among women (Andersson et al., 2013; Bartoli et al., 2014; Slutske, 2005; Young et al., 2005) and young people, even those below the legal drinking age (NIAAA, 2021). Some studies in Italy, mainly conducted on university students, show that this country is aligned with international trends on binge drinking among young adults (D'Alessio et al., 2006; De Salvia et al., 2019; Di Grande et al., 2000). Moreover, according to the Italian Ministry of Health (2019), $2.1 \%$ of consumers aged 18-24 engaged in "habitual excess consumption" (i.e. the consumption of two alcoholic units a day, equivalent to two glasses of wine for men and one for women). This percentage increased to $33.7 \%$ for men and $7.9 \%$ for women over the age of 65 . However, there are no indications regarding the intermediate classes.

Despite the urgency of protecting public health, and therefore the need for interventions that reduce drinking, alcohol is one of the most advertised products in the world. Already commonplace on traditional media, advertisements for alcoholic beverages have proliferated with the advent of digital and social media (e.g. Carroll et al., 2005). Policymakers need new ways to limit the negative effects of excessive alcohol consumption, especially for young consumers. Besides adopting measures such as restricting the legal drinking age and taxing alcoholic beverages, many countries have introduced alcohol warning labels to reduce beverage consumption (International Alliance for Responsible Drinking, 2016), but there is still a lack of consensus and consistency about the best approach. For example, as found by Talukdar and Lindsey (2013), price changes are not effective tools. In fact, for unhealthy food, demand sensitivity is greater for a price decrease than for a price increase.

In the last two decades, governments have created and refined multiple types of warning labels (Guido, 2001). First, there is a simple claim: a textual phrase that focuses on consumers, without adding information about the product or the consequences of its abuse. An example is "Drink with moderation" used in Argentina or Portugal (Stockwell, 2006). Similar to claims, textual warning labels provide information in text format that describes the content of the product or the consequences of its excessive consumption. Finally, pictorial warning labels are images, photos or drawings that add more information to the product, usually about the possible long-term consequences of its consumption (Al-hamdani, 2014). All labels that use health risks as a deterrent are usually called health warning labels. Furthermore, these can be 
distinguished as positive warning labels (e.g. "Reduce your drinking to reduce your risk of cancer") and negative warning labels (e.g. "Warning: alcohol increases your risk of cancer") (Pettigrew et al., 2014; Rosenblatt et al., 2019).

After some initial controversies about the labels' effectiveness (Scholes-Balog et al., 2012), many studies have confirmed that health warning labels facilitate a negative perception of smoking and reduce the appeal of cigarettes (Wigg and Stafford, 2016), thereby shaping consumer behaviour. Similarly, scholars have found that using images of the effects of alcoholic and food products has positive repercussions (Al-hamdani and Smith, 2017a; Pechey et al., 2020). Notably, these authors demonstrated a substantial difference between the use of textual warnings and pictorial warning labels in terms of arousal and awareness: images increase negative awareness and negative emotional arousal, heightening the warning recognition and perceptions of alcohol risks (Al-hamdani and Smith, 2017a; Pechey et al., 2020). Instead, text messages do not have significant cognitive effects. However, the authors also showed that people express greater acceptance towards text messages than unpleasant images. This can be problematic for pictorial warning labels, as they generally represent different types of disease and negative conditions (Pettigrew et al., 2014).

This paper offers an alternative to the use of images that lead to excessive negative arousal. Instead, we propose replacing images of the effects of serious diseases with images of food that represent the equivalent caloric content of the alcoholic beverage. In this way, the risk of obesity can be leveraged as a deterrent against alcohol abuse. This method of representation would also solve another problem: As is known in the literature, consumers can struggle with mentally managing quantitative information that is expressed numerically, such as nutritional tables (Cowburn and Stockley, 2004).

Through two different studies conducted in Italy on two samples of respondents - a questionnaire-based study and a neuromarketing study - we examined the intention to purchase two drinks (alcoholic beverages) with different caloric content following exposure to three types of warning labels: (1) a claim (a responsibility warning statement affirming "drink responsibly"); (2) a textual warning label (a synthetic nutritional table indicating the number of kilocalories contained in the alcoholic beverage); and (3) a pictorial warning label (a more acceptable image of a food product with a caloric content equivalent to the reference drink). With these two studies, we will investigate if the high calorie content of food can be used as a deterrent against alcohol abuse. We will then evaluate the effectiveness of each of the three warning labels and the underlying physiological motivations.

\section{Theoretical background and hypotheses development}

\subsection{Cognitive responses to warnings labels}

Since the birth of warning labels, various authors have studied their effect on individuals' perceptions towards both the product itself (i.e. the mental associations related to the appearance of the product) and the people who consume it (in terms of their expected personality). In the early 1990s, a pioneering study hypothesised a correlation between one's attitude towards drinking alcohol and attitude towards warning labels; the authors found that the latter is linked with cognitive responses (i.e. thoughts) that help to worsen one's attitude towards drinking after seeing the warning label (Craig et al., 1993). While that research specifically used claims, other studies have deepened its findings using tobacco products. Borland et al. (2009) found an increase in cognitive responses when warning labels incorporate photos of health damage. In these cases, consumers spend more time thinking about health risks, mainly due to an increase in negative emotions such as fear, disgust and anger (Brewer et al., 2016), alongside the heightened state of arousal (agitation) (Romer et al., 2018). Consequently, people experience a change in their perceptions of the product - specifically, a reduced opinion about the benefits (satisfaction) obtained by its consumption (Romer et al., 2018).

\section{Pictorial warning labels}


$\mathrm{BFJ}$

123,13

Research has obtained similar results with regard to alcoholic products. Generally, the presence of warning labels (text or pictorial) leads to a less positive perception of both the alcoholic product and alcohol consumers (Al-hamdani and Smith, 2015). In this context, Wigg and Stafford (2016) identified a relationship between the use of images related to health damage and the perception of risk, which is mediated by fear.

Finally, other investigations have analysed the size of the images on the warning label and the health warning severity influences (Al-hamdani and Smith, 2017b). Larger images accentuate the negative effect of the label on the product's perception, while images with severe contents (such as liver cirrhosis, brain damage, mental illness, cancer, road accidents, and risk to an unborn child) increase the warning's effectiveness, motivation to reduce alcohol consumption, self-efficacy to drink less, and susceptibility to the risk (Sillero-Rejon et al., 2018).

In conclusion, it is possible to affirm that warning statements, such as claims or metaphors, are ineffective at reducing alcohol consumption if they lack a strong cognitive stimulus (Bayliss and Krieger, 2018). Furthermore, consumers may not distinguish warning claims from nutritional information, nutritional claims or ingredient lists, thereby creating confusion (BEUC, 2015). For this reason, we assume that

H1. Warning statements in the form of claims used to prevent abuse in the consumption of alcohol do not influence the intention to purchase alcoholic beverages.

\subsection{Nutrition labels in food packaging}

Providing nutritional information, such as energy content, allows consumers to better understand what they consume and maintain a healthy lifestyle. Through nutritional labelling, policymakers hope to encourage consumers to make more rational choices (EUROCARE, 2018). Various types of nutritional labels have been proposed in both the literature and by institutions. The classic back labels have been supplemented with front-of-package (hereafter, FOP) labels, as well as symbols such as traffic lights, stars, and other scoring systems (Gorski Findling et al., 2018).

Researchers have extensively analysed the impact of each method. Although consumers support nutritional labels and have a positive attitude towards them (Annunziata et al., 2016a), they prefer a short FOP to a back label (van Herpen and van Trijp, 2011) and pictures and symbols with essential numerical information rather than text (Carrillo et al., 2014). Consumers especially exhibit these preferences when needing to compare products (Newman et al., 2018), as it is easier to interpret symbols and colours than nutrient-specific labels that only emphasise numeric information such as the Guidelines Daily Amounts (GDAs) or the Reference Intake (RI) (European Union, 2011; Hersey et al., 2013).

Some studies have confirmed that nutrition labels, GDA, and ingredients lists are the main sources of information used to evaluate calorie, fat and sugar content (Grunert et al., 2010). In general, consumers have difficulties with quantitative information (Cowburn and Stockley, 2004), especially with respect to GDA (Campos et al., 2011) and when they are under time pressure (Annunziata et al., 2016a).

Contrary to what policymakers had hoped, nutritional information (Bui et al., 2008) and FOP (Kim et al., 2012) cause consumers to underestimate the amount of calories and carbohydrates contained in beverages (such as wine), leading to an increase in consumption. For these reasons, we hypothesise that:

H2. The numerical caloric content shown on a textual warning label does not influence the intention to purchase an alcoholic beverage.

\subsection{Nutritional information presented with a pictorial warning label}

By shifting attention overseas, the US Institute of Medicine (2005) recommended the calorie labelling of menus as a strategy to counteract obesity and the Food and Drug Administration 
wrote formal rules adopted by companies during 2018. As indicated above, consumers have difficulty correctly perceiving numerical information. For instance, they may overestimate the number of calories when food is scarce (Salerno and Sevilla, 2019) or underestimate them in relation to certain products like wine (Bui et al., 2008). This is why pictorial warning labels may be better at explaining the caloric content of a beverage and thereby discourage excessive consumption.

A pictorial warning label could be intended as an image able to represent the caloric content of a food product using another product, as an efficient cognitive stimulus, equivalent in terms of caloric content. Pictorial warning labels could help to understand the content of a beverage, and, relying on caloric content and therefore on the risk of obesity, discourage excessive alcohol consumption. In particular, positively framed images, also effective (Rosenblatt et al., 2019), would be more accepted by producers granted the visibility of the pictorial warning label is affected by the bottle packaging, the product logo, and other illustrations (Thomsen and Fulton, 2007). In a situation where these competing elements are not present, such as the presentation of a cocktail on a menu or for products without packaging, we assume that

H3. The use of pictorial warning labels representing the numerical caloric content decreases the intention to purchase an alcoholic beverage.

\subsection{Physiological effects of pictorial warning labels}

Emotional stimuli activate brain regions such as the medial prefrontal $(\mathrm{mPFC})$ and the anterior cingulate cortices (ACCs) (Etkin et al., 2011). Bush et al. (2000) connected the ACC, as part of the brain's frontal and limbic connectivity, to the integrating signals processes, both emotional and cognitive. In particular, the dorsal part of the ACC is connected with the prefrontal cortex and parietal cortex, making it a central station for processing stimuli; the ventral part of the ACC is connected with the amygdala, nucleus accumbens, hypothalamus, hippocampus, and anterior insula, and is involved in processing emotions and motivational information (Allman et al., 2001; Posner and Di Girolamo, 1998). Moreover, other functions are attributed to the ACC, such as attention, modulation of emotional responses and motivation (Bush et al., 2000; Nieuwenhuis et al., 2001; Posner and Di Girolamo, 1998), where motivation is considered to be the experience of desire or aversion (Ryan and Deci, 2000). Therefore, the physiological connection of the ACC with the prefrontal cortex suggests a connection between motivational stimuli and emotions. Since the rhythms of the right and left prefrontal regions of the cerebral cortex can be compared to distinguish positive emotional states from negative ones (Berčik et al., 2015), we predict the following relationship:

H4. Pictorial warning labels increase brain activation in the left prefrontal region of the cerebral cortex and, therefore, negative emotions.

\section{Study 1}

\subsection{Procedure}

In order to demonstrate that the impact of the pictorial warning labels is invariant with respect to the caloric content (used as a factor), the experiment was designed considering two consumer goods (Figure 1): the "Mojito" cocktail, characterised by a low caloric content (143 Kcal), and the "Piña Colada" cocktail, with a high caloric content (490 Kcal). Both stimuli differ in their ingredient composition, but have similar alcohol volume (National Institutes of Health - U.S. Department of Health and Human Services, 2020). We used three types of warning labels. The claim was created by a panel of eight marketing experts. The panel featured experts in the disciplines of marketing $(N=3)$, food marketing $(N=2)$, advertising $(N=1)$, consumer psychology $(N=1)$ and nutrition $(N=1)$. To attract participants' attention 
$\mathrm{BFJ}$

123,13

474

and avoid methodological biases (Podsakoff et al., 2003) we chose "Drink responsibly" (Farace et al., 2020; Smith et al., 2014). The textual warning label showed the numeric value of the caloric content of the product. The pictorial warning label showed a food product, equivalent in caloric terms. As in other studies (Chandon and Wansink, 2007a, b), the panel of marketing experts selected a large consumption food product: The Big Mac McDonald's (509 Kcal). For the high caloric content stimulus, the pictorial warning label was used as a whole. Instead, for the stimulus with low caloric content, the pictorial warning label was cut and longitudinally reduced by $62 \%$ (Figure 2 ).

A structured questionnaire was administered to a sample of respondents who were randomly selected among Italian residents in natural consumption places (e.g. lounge bar in the city centre), for four weeks, between 19:00 and 24:00.

We hired five well-instructed research assistants who chose a suitable time for administering questionnaires. In order to reduce evaluation apprehension (Podsakoff et al., 2003), the questionnaire guaranteed anonymity, that there were no right or wrong answers, and that data would only be used for academic purposes.

The questionnaire first informed participants about the study's purpose and asked them to confirm or not that they knew about the selected products (participants not informed were excluded from the experiment). Then, the questionnaire displayed the product image alongside various information elements in a randomised fashion. In line with the expectancyvalue theory (Ajzen and Fishbein, 1980), we adopted the standard procedure for calculating the purchase intention. This procedure requires that the purchase intention indicates the products between the importance attributed to the individual beliefs and the probability attributed to their occurrence. Particularly, subjects were asked to think about the product and rate their purchase intention by indicating, on a seven-point Likert scale ( 1 = "Not at all strong" to 7 = "Very strong"), the strength of their intention to buy the product and their likelihood of buying the product. Both scores were multiplied to derive a trusted assessment of the behavioural intention, in accordance with a consolidated procedure in expectancyvalue models (see, e.g. Ajzen and Fishbein, 1980). Hence, a non-continuous index ranging from +1 to +49 has been obtained. As in other similar studies (see, for example, Guido et al., 2017), since the index is not continuous, the results show a high standard deviation. After that, the average values for all respondents were calculated and used to test the hypotheses.

Afterwards, respondents were asked to classify their degree of drinking through one of the following categories: "Abstemious" if he/she does not consume alcoholic beverages; "Light drinker" if he/she consumes up to three alcoholic beverages a week; "Moderate drinker" if he/she consumes three to eleven alcoholic drinks per week, and "Heavy drinker" if he/she consumes more than eleven alcoholic drinks per week (Thompson et al., 2013). Lastly, respondents provided their socio-demographic data (gender, age, income and education level).

Figure 1.

Stimuli considered in the study

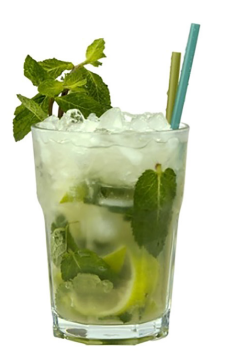

мOJTO

Ingredients:

2 fl.oz white rum;

2 fl.oz lime juice;

2 fl.oz tonic

Brown sugar;

Alcohol Volume: 13.3\%

Kcal: 143

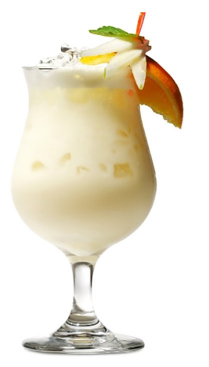

PIÑA COLADA

Ingredients:

3 fl.oz white rum;

2 fl.oz coconut juice;

$4 \mathrm{fl} . \mathrm{oz}$ ananas juice

Alcohol Volume: $13.3 \%$

Kcal: 490 


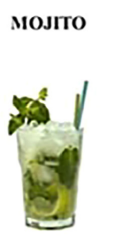

PIÑA COLADA

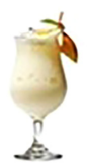

(a)

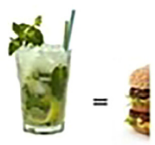

(b)

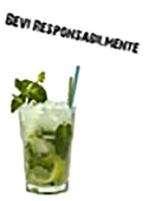

(c)

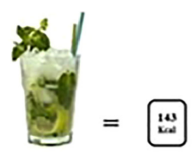

(d)
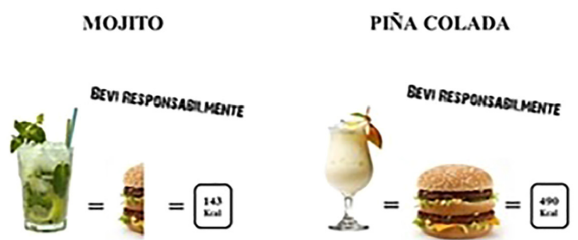

(e)
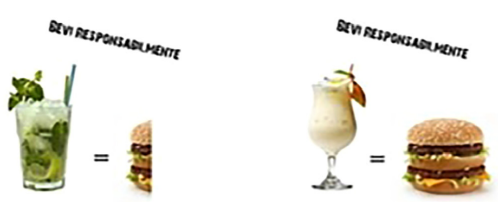

(f)
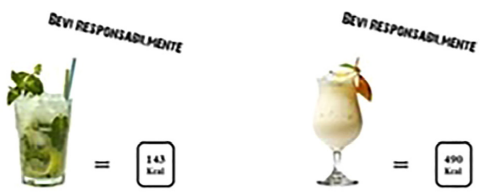

(g)

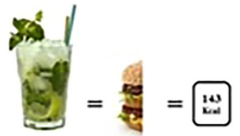

(h)
Pictorial warning labels

475
Figure 2.

Combinations of warnings, from (b) to (h), that can be obtained with pictorial warning label, textual warning label and claim. The first one, case (a), is without any labels and is used for the control group

The questionnaire had eight versions that paired one of the two drink images with a claim, textual warning label, or pictorial warning label, some combination thereof, or no label at all (Figure 2): (1) the two stimuli (the "Mojito" and the "Piña Colada") without a label (case $a$ ); (2) the stimuli alongside the pictorial warning label (case b); (3) the stimuli alongside the claim (case c); (4) the claim and the pictorial warning label (case f); (5) a textual warning label next to the stimulus (case $d$ ); (6) both the textual warning label and the pictorial warning label (case $h$ ); (7) the claim and the textual warning label (case g); and finally, (8) an image showing all the types of information (case $e$ ) (Figure 2).

\subsection{Sample}

This research was conducted using a sample of 480 randomly selected healthy respondents: $55 \%$ men and $45 \%$ women, all residents of Italy. In order to participate, respondents had to be older than 18 and possess knowledge of the two products. Of the total, $24.4 \%$ were between 18 and 22 years old, $43.5 \%$ were between 23 and 27 years old, $21.3 \%$ were between 28 and 37 years old, $5.2 \%$ were between 38 and 47 years old, and the remaining $5.6 \%$ were older than 47. In terms of income, $54.1 \%$ had an income below $€ 10,000,32.3 \%$ between $€ 10,000$ and $€ 20,000,10.9 \%$ between $€ 20,000$ and $€ 50,000$, and $2.7 \%$ greater than $€ 50,000$. In terms of educational level, $60.2 \%$ of participants had a degree below university, while the remaining 
$\mathrm{BFJ}$ 123,13

\section{6}

$39.8 \%$ had a university degree or higher. Finally, $20.4 \%$ were non-drinkers, $64.6 \%$ were light drinkers $11.9 \%$ were moderate drinkers and the remaining $3.2 \%$ were heavy drinkers.

The sample aligns with the general profile data of Italian consumers (ISTAT, 2020): $57.9 \%$ men and $42.1 \%$ women; $23.9 \%$ are between 18 and 24 years old, $13.1 \%$ are between 25 and 29 years old, $12.8 \%$ are between 30 and 34 years old, $12.5 \%$ are between 35 and 44 years old, and the remaining $37.4 \%$ are older than 45 . The data differ only with regard to educational level: $78.6 \%$ of Italian consumers have a university degree or higher. However, in this study, the $39.8 \%$ of participants with a university degree or higher is justified by the low level of local education (ISTAT, 2020). As mentioned above, in our study, heavy drinkers (more than 11 drinks per week, approximately two per day) accounted for $3.2 \%$ of the sample (1865 years old). This result is in line with the $2.1 \%$ of consumers aged 18-24 engaged in "habitual excess consumption" declared by the Italian Ministry of Health (2019).

Table 1 summarizes the sample's characteristics.

\subsection{Analysis and results}

We conducted a series of ANOVA alongside Fisher's significance test (Tables 2 and 3).

\begin{tabular}{llr}
\hline & Category & Sample $(\%)$ \\
\hline \multirow{2}{*}{ Gender } & Male & 55 \\
& Female & 45 \\
Age cohort (years) & $18-22$ & 24.4 \\
& $23-27$ & 43.5 \\
& $28-37$ & 21.3 \\
Annual income $(€)$ & $38-47$ & 5.2 \\
& $>47$ & 5.6 \\
& $<10,000$ & 54.1 \\
Education & $10,000-20,000$ & 32.3 \\
Alcohol consumption & $20,000-50,000$ & 10.9 \\
& $>50,000$ & 2.7 \\
& University degree or higher & 60.2 \\
& High school diploma or lower & 39.8 \\
& Non-drinkers & 20.4 \\
& Light drinkers & 64.6 \\
& Moderate drinkers & 11.9 \\
& Heavy drinkers & 3.2
\end{tabular}

Table 1.

Individual, situational and behavioural characteristics of survey respondents
Table 2.

Purchase intention in absence/presence of pictorial warning label, and claim conditions, for the stimulus with low caloric content

\begin{tabular}{|c|c|c|c|c|c|c|c|c|c|}
\hline \multirow{2}{*}{\multicolumn{2}{|c|}{ Stimulus with low caloric content }} & \multicolumn{8}{|c|}{ Claim } \\
\hline & & \multicolumn{5}{|c|}{ Absent } & \multicolumn{2}{|c|}{ Present } & ANOVA \\
\hline $\begin{array}{l}\text { Textual warning } \\
\text { label }\end{array}$ & $\begin{array}{l}\text { Pictorial warning } \\
\text { label }\end{array}$ & $M$ & SD & $F$ & $p$ & $M$ & SD & $F$ & $p$ \\
\hline \multirow[t]{2}{*}{ Absent } & Absent & 15.41 & 13.96 & - & - & 13.91 & 13.12 & 0.188 & 0.665 \\
\hline & Present & 11.64 & 13.08 & 4.773 & 0.029 & 11.79 & 13.25 & 0.006 & 0.936 \\
\hline \multirow[t]{2}{*}{ Present } & Absent & 16.84 & 15.84 & 3.076 & 0.080 & 17.37 & 12.87 & 0.004 & 0.952 \\
\hline & Present & 14.85 & 13.80 & 0.001 & 0.974 & 13.29 & 14.24 & 0.469 & 0.494 \\
\hline
\end{tabular}

Total: $\mu=14.376 ; \delta=13.818$;

Note(s): $M=$ arithmetic mean; $\mathrm{SD}=$ standard deviation; $F=$ probability distribution; $\not p=$ significance 
According to hypothesis H1, the purchase intention should not be influenced by the presence of the claim "Drink Responsibly". In order to verify H1, we developed two ANOVA: the former for the stimulus "Mojito" (low caloric content) and the latter for the stimulus "Piña Colada" (high caloric content). The results confirm $\mathrm{H} 1$ for both the stimulus with low caloric content $(M=15.41, M=13.91 ; N=120 ; F=0.188, p>0.05)$ and the stimulus with high caloric content $(M=12.00, M=9.46 ; N=120 ; F=0.001 ; p>0.05)$. In line with other studies (Farace et al., 2020; Smith et al., 2014), this result indicates that the claim does not inhibit the purchase intention of alcoholic beverages, regardless of caloric content.

Analogously, the second hypothesis (H2) assumed that the intention to purchase is not influenced by the presence of the textual warning label. The lack of a significant difference between the means of the groups would seem to confirm $\mathrm{H} 2$, for both the stimulus with low caloric content $(M=15.41, M=16.84 ; N=120 ; F=3.076, p>0.05)$ and the stimulus with high caloric content $(M=12.00, M=9.72 ; N=120 ; F=0.043, p>0.05)$. Therefore, we feel confident in saying that the textual warning label does not reduce the intention to buy alcoholic beverages, regardless of caloric content.

The third hypothesis (H3) assumed that the pictorial warning label significantly reduces the purchase intention. For both the stimulus with low caloric content $(M=15.41, M=11.64$; $N=120 ; F=4.773, p<0.05)$ and the stimulus with high caloric content $(M=12.00, M=7.28$; $N=120 ; F=4.481, p<0.05)$, there was a significant difference in the averages of the groups. These results support $\mathrm{H} 3$ and suggest that the pictorial warning label is relevant to reducing purchase intention, regardless of caloric content.

Figure 3 compares the purchase intent in situations where the pictorial warning label and the claim for the stimulus with low caloric content are present/absent with cases where the textual warning label is absent (Figure 3a) or present (Figure 3b). In particular, Figure 3a shows that the presence of the pictorial warning label significantly reduces purchase intention more than the absence of either the claim or textual warning label. Also, in case of joint appearance of pictorial warning label and claim, there is not a significant reduction of the purchase intention. Figure $3 \mathrm{~b}$ shows that a textual warning label does not significantly decrease purchase intention even if combined with other warnings (both claims and pictorial warning labels) Figure 3c compares the purchase intentions in cases where the pictorial warning label is either present or absent next to a stimulus with high caloric content. Figure 3d presents the same comparison for claim. Figure 3c shows the same situation represented in Figure 3a, but with reference to the stimulus with high caloric content. It appears that the textual warning label alone causes no significant decrease in purchase intentions for either type of stimuli (Figure $3 \mathrm{~b}$ and d).

In addition, Tables 4 and 5 showcase the effects of each possible interaction between the variables used. The results show that using the pictorial warning label in conjunction with the textual warning label $(F=3.993, p=0.049$ for the stimulus with low caloric content, and

\begin{tabular}{|c|c|c|c|c|c|c|c|c|c|}
\hline \multirow{3}{*}{\multicolumn{2}{|c|}{ Stimulus with high calorie content }} & \multicolumn{8}{|c|}{ Claim } \\
\hline & & \multicolumn{5}{|c|}{ Absent } & \multicolumn{2}{|c|}{ Present } & \\
\hline & & \multicolumn{5}{|c|}{ ANOVA } & \multicolumn{3}{|c|}{ ANOVA } \\
\hline $\begin{array}{l}\text { Textuul with nig } \\
\text { Textual warning } \\
\text { label }\end{array}$ & $\begin{array}{l}\text { Pictorial warning } \\
\text { label }\end{array}$ & $M$ & SD & $F$ & $p$ & $M$ & $\mathrm{SD}$ & $F$ & $p$ \\
\hline \multirow[t]{2}{*}{ Absent } & Absent & 12.00 & 12.75 & - & - & 9.46 & 9.50 & 0.001 & 0.982 \\
\hline & Present & 7.28 & 8.87 & 4.481 & 0.035 & 8.62 & 11.71 & 0.200 & 0.655 \\
\hline \multirow[t]{2}{*}{ Present } & Absent & 9.72 & 12.16 & 0.043 & 0.835 & 11.23 & 8.15 & 0.277 & 0.599 \\
\hline & Present & 8.86 & 11.05 & 0.198 & 0.657 & 8.45 & 12.62 & 1.784 & 0.182 \\
\hline
\end{tabular}

Total: $\mu=9.391 ; \delta=10.937$;

Note(s): $M=$ arithmetic mean; $\mathrm{SD}=$ standard deviation; $F=$ probability distribution; $\not p=$ significance

\section{Pictorial warning labels}

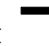

(1)


BFJ

123,13

478

Figure 3.

The purchase intention in absence/presence of pictorial warning label, and claim conditions, for the stimulus with low caloric content, and for the stimulus with high caloric content, in absence and in presence of the textual warning label

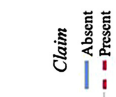
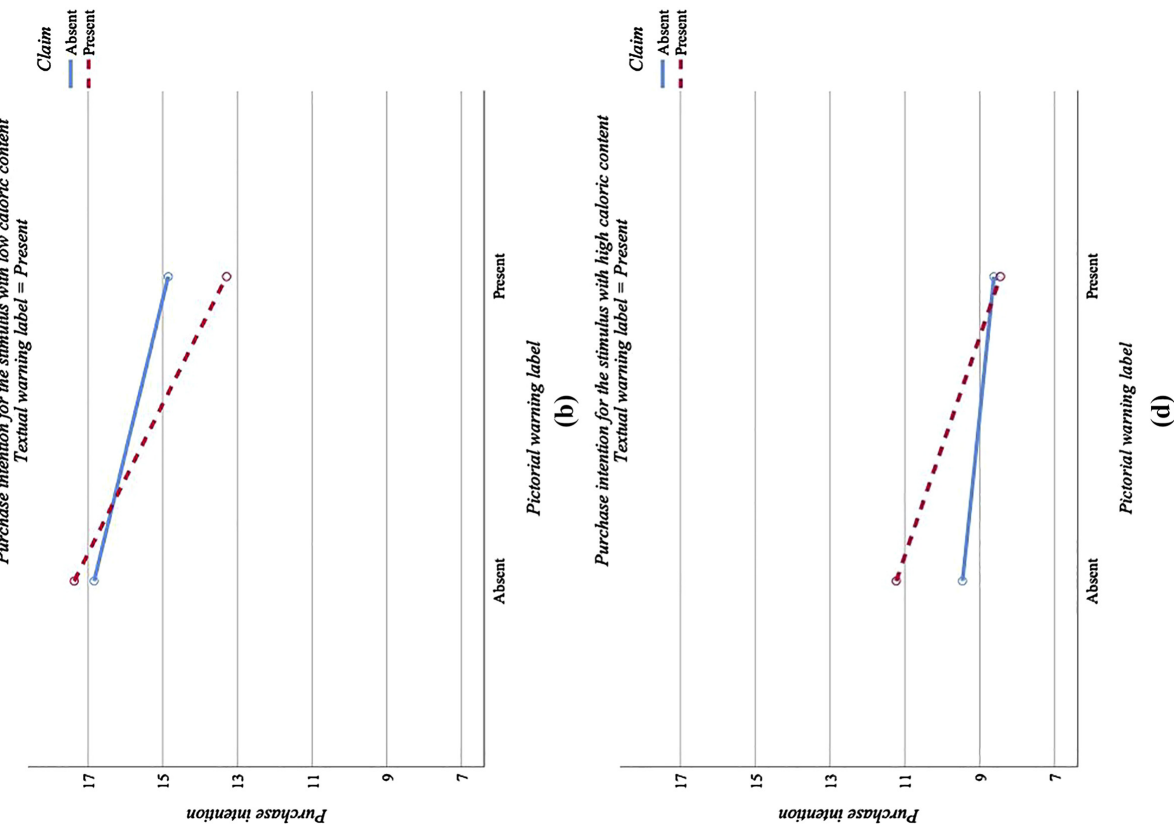

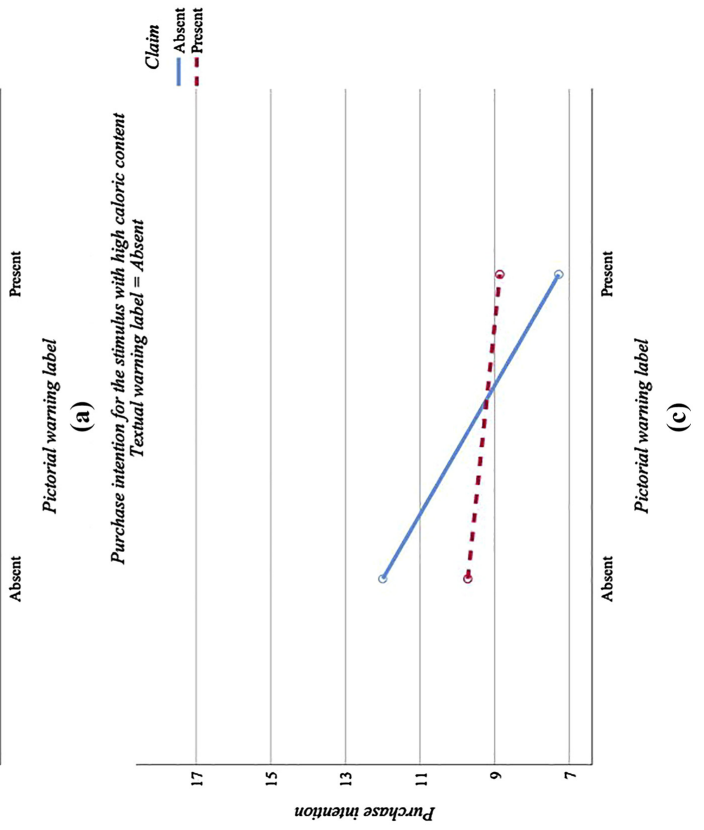


$F=4.373, p=0.040$ for the stimulus with high caloric content) or with the claim $(F=4.211$, $p=0.044$ for the stimulus with low caloric content, and $F=5.429, p=0.023$ for the stimulus with high caloric content) has the same effect as using the pictorial warning label by itself. The use of all three warnings is not effective ( $F=0.263, p=0.608$ for the stimulus with low caloric content, and $F=0.109, p=0.742$ for the stimulus with high caloric content). Finally, using the claim in conjunction with the textual warning label also seems to be ineffective $(F=0.013$, $p=0.910$ for the stimulus with low caloric content, and $F=0.011, p=0.916$ for the stimulus with high caloric content).

\section{Study 2}

\subsection{Procedure and experimental design, environment and equipment}

In order to evaluate participants' emotional reactions to the stimuli considered in the first study, we conducted a neuromarketing experiment using the Electroencephalography (EEG) technique. The experiment consists of a $2 \times 2 \times 2$-factor within-subject design using the same products considered in Study 1. Using the eight conditions per product depicted in Figure 2, we developed a video lasting 3'16". The first four seconds of the video presented a black screen, followed by the random sequence of images interspersed with five seconds of black screen, and concluded with a "Thank You" screen (Figure 4).

The experiment was conducted at the neurology unit of an Italian Hospital under the supervision of a neurologist. In a soundproof room, with lights off and windows closed, the

\begin{tabular}{|c|c|c|c|c|c|c|}
\hline Source & $\begin{array}{c}\text { Sum of squares } \\
\text { Type III }\end{array}$ & $F$ & $\begin{array}{l}\text { Average of the } \\
\text { square }\end{array}$ & $F$ & $p$ & $\begin{array}{c}\text { Partial } \\
\eta^{2}\end{array}$ \\
\hline Correct model & 2615.553 & 7 & 373.650 & 1.839 & 0.078 & 0.018 \\
\hline Intercept & 89525.790 & 1 & 89525.790 & 440.593 & 0.000 & 0.186 \\
\hline Pictorial warning label $\times$ claim & 10.471 & 1 & 10.471 & 4.211 & 0.044 & 0.373 \\
\hline $\begin{array}{l}\text { Pictorial warning label } \times \text { textual } \\
\text { warning label }\end{array}$ & 778.229 & 1 & 778.229 & 3.993 & 0.049 & 0.398 \\
\hline Claim $\times$ textual warning label & 2.611 & 1 & 2.611 & 0.013 & 0.910 & 0.001 \\
\hline $\begin{array}{l}\text { Pictorial warning } \\
\text { label } \times \text { claim } \times \text { textual warning label }\end{array}$ & 53.487 & 1 & 53.487 & 0.263 & 0.608 & 0.001 \\
\hline Error & 90014.904 & 443 & 203.194 & & & \\
\hline Total & 182432.000 & 451 & & & & \\
\hline Corrected total & 92630.457 & 450 & & & & \\
\hline
\end{tabular}

Pictorial warning labels
Table 4. Interaction effects between pictorial warning labels, textual warning labels and claim, for the stimulus with low calorie content

\begin{tabular}{|c|c|c|c|c|c|c|c|}
\hline Source & $\begin{array}{l}\text { Sum of squares } \\
\text { Type III }\end{array}$ & $F$ & $\begin{array}{l}\text { Average of the } \\
\text { square }\end{array}$ & $F$ & $p$ & $\begin{array}{l}\text { Partial } \\
\eta^{2}\end{array}$ & \\
\hline Correct model & 704.070 & 7 & 100.581 & 0.800 & 0.078 & 0.028 & \\
\hline Intercept & 38256.277 & 1 & 38256.277 & 304.174 & 0.000 & 0.026 & \\
\hline Pictorial warning label $\times$ claim & 57.728 & 1 & 57.728 & 5.429 & 0.023 & 0.453 & \\
\hline $\begin{array}{l}\text { Pictorial warning label } \times \text { textual } \\
\text { warning label }\end{array}$ & 179.812 & 1 & 179.812 & 4.373 & 0.040 & 0.472 & $\begin{array}{r}\text { Table } 5 . \\
\text { Interaction }\end{array}$ \\
\hline Claim $\times$ textual warning label & 1.396 & 1 & 1.396 & 0.011 & 0.916 & 0.000 & $\begin{array}{l}\text { Interaction effects } \\
\text { between pictorial }\end{array}$ \\
\hline $\begin{array}{l}\text { Pictorial warning } \\
\text { label } \times \text { claim } \times \text { textual warning label }\end{array}$ & 13.678 & 1 & 13.678 & 0.109 & 0.742 & 0.001 & warning labels, textual \\
\hline Error & 55716.635 & 443 & 125.771 & & & & claim, for the stimulus \\
\hline Total & 94737.000 & 451 & & & & & with high calorie \\
\hline Corrected total & 56420.705 & 450 & & & & & content \\
\hline
\end{tabular}


BFJ 123,13

\section{0}

Figure 4.

Video

Plate 1.

Experimental environment

video was projected onto a white wall using a video projector. Participants sat in an armchair placed 2 metres from the wall. Then, via the EEG tool, each participant was connected to a computer that recorded the data (Plate 1). Participants' electrical brain activity was measured by the Micromed EEG Brain Quick, with 16 electrodes positioned on the frontal, prefrontal, parietal and temporal area, in accordance with the International 10-20 System (Cacioppo et al., 2016; Jasper, 1958) for placing scalp electrodes in the context of an EEG test.

\subsection{Sample}

The research was conducted on a convenience sample consisting of 34 Italian participants, randomly selected from among students and adults willing to dedicate four free hours. The interviewers intercepted potential respondents at various public areas (including busy streets, shopping malls, public parks and bus stations) and, after explaining the experimental procedure, invited them to participate. The interviewers immediately accompanied willing respondents to the local hospital. In order to match the sample characteristics from Study 1, we evenly split the sample between men and women aged between 21 and 45 years $(M=31.42$; $\mathrm{SD}=5.81$ ). In terms of education, $61.8 \%$ of the sample had a university degree or higher, while the remaining $38.2 \%$ had a lower academic qualification. Regarding annual income, the sample was divided as follows: $20.6 \%$ of participants had an income lower than $€ 10,000 ; 35.3 \%$ had an income between $€ 10,000$ and 20,$000 ; 29.4 \%$ between $€ 20,000$ and $€ 50,000$; and $14.7 \%$ had an income higher than $€ 50,000$. Finally, $5.9 \%$ were non-drinkers, $44.1 \%$ were light drinkers, $32.4 \%$ were moderate drinkers and the remaining $17.6 \%$ were heavy drinkers.

In order to be considered suitable for the purpose of the experiment, the candidates had to possess the following prerequisites: normal or corrected normal vision, an absence of personal and family psychopathologies, and a non-pathological EEG layout.

\subsection{Informed consent and behavioural rules}

Participants were informed about the scientific aims of the experiment; the behavioural protocol in accordance with the Code of Ethics of the World Medical Association and
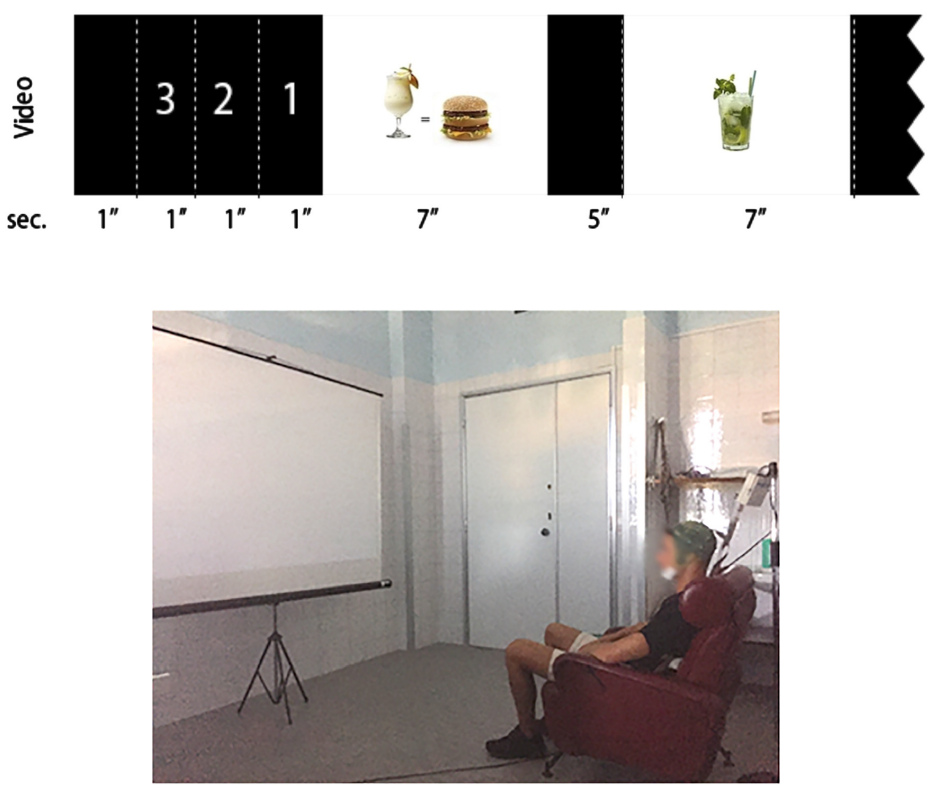
approved by the Ethics Committee of the hospital; the risks and advantages deriving from participation in the experiment; the law on privacy, and the freedom to give up participating in the experiment at any time. The candidates who signed the informed consent were asked to read and comply with certain behavioural rules ("Stay focused on the video and not be distracted by others"; "Do not close your eyes for long periods of time"; "Avoid talking during the test, except for urgent requests"; and "Do not carry cell phones or other devices capable of emitting sound").

\subsection{Data analysis}

Muscle activity, sounds and eye blinks could produce artifacts in the EEG data that could invalidate the results. With the help of the neurologist, data were carefully inspected to detect artifacts or other signal noises.

The comparison of the $\alpha$ and $\beta$ rhythms of the right prefrontal (electrode $\mathrm{F} 4_{\alpha}$ and $\mathrm{F} 4_{\beta}$ ) and left prefrontal (electrode $\mathrm{F} 3_{\alpha}$ and $\mathrm{F} 3_{\beta}$ ) regions of the cerebral cortex, which reflect emotional regulation and conscious states (Berčik et al., 2015), allows to distinguish positive emotional states from negative ones, as well as measure the participant's level of satisfaction, or valence $(V)$ (Petrantonakis and Hadjileontiadis, 2011). A low value of $V$ represents sadness and a high value of $V$ represents happiness (Guzel Aydin et al., 2016). $V$ is calculated using the formula

$$
V=\frac{F 4_{\alpha}}{F 4_{\beta}}-\frac{F 3_{\alpha}}{F 3_{\beta}}
$$

Through the Matlab programming environment, coupled with the use of the Signal Processing, Wavelet, EEGLab and Statistics and Machine Learning packages, we performed the decomposition of the cerebral rhythm with the "wavelet function" of the "wavedec" function (Guzel Aydin et al., 2016). Subsequently, the valence and the average valence (Vm) were calculated for each time interval in which the video was shown, producing a single value able to summarise the participant's emotional reaction. The following scale was used to classify the reaction: values of $V m$ lower than -0.5 corresponded to a prevalence of negative emotions; values of $V m$ between -0.5 and +0.5 indicated a neutral reaction; values of $V m$ above +0.5 reflected a prevalence of positive emotions. To compare the valence in each condition, we performed a post hoc least significance difference (LSD) test. This test involves a systematic procedure for comparing all possible pairs of group means using a Student's $t$ (Duncan, 1965), which is suitable for the considered sample since the EEG data follow a normal distribution (Shapiro-Wilk test, $p>0.05$ ).

\subsection{Results}

The results of the post hoc LSD analysis confirmed an increase of negative emotions (i.e. a brain activation in the left prefrontal region of the cerebral cortex due to stimulation with a pictorial warning label; Table 6), thus confirming hypothesis H4. However, the results for the stimulus with high caloric content demonstrated a decrease in valence compared to the control condition (without any kind of warnings) across other conditions: pictorial warning label $(\Delta M=-43.45 ; p=0.040)$; claim and pictorial warning label $(\Delta M=-41.74 ; p=0.049)$; and all three warnings $(\Delta M=-49.50 ; p=0.021)$. In the case of the stimulus with low caloric, the valence significantly decreased only in the case of the condition containing all three warnings $(\Delta M=-134.64 ; p=0.048)$. Furthermore, the presence of claim and textual warning labels had no effect on valence, thus motivating the hypotheses $\mathrm{H} 1$ and $\mathrm{H} 2$.

Finally, Figures 5 and 6 represent the proportions of participants who manifested a specific emotion to each of the eight conditions for both stimuli. For the stimulus with low caloric content, the proportion of participants who showed positive emotions during the

\section{Pictorial warning labels}


$\mathrm{BFJ}$ 123,13

Figure 5.

Proportions of participants who demonstrated positive, neutral and negative emotions in each condition for the stimulus with low caloric content

\section{Figure 6.}

Proportions of participants who demonstrated positive, neutral and negative emotions in each condition for the stimulus with high caloric content

\begin{tabular}{lrrrrrr}
\hline & \multicolumn{3}{c}{ Stimulus with low calorie content } & \multicolumn{3}{c}{ Stimulus with high calorie content } \\
& \multicolumn{1}{c}{$M(\mathrm{SD})$} & \multicolumn{1}{c}{$\Delta M$} & \multicolumn{1}{c}{$\boldsymbol{c}$} & \multicolumn{1}{c}{$M(\mathrm{SD})$} & \multicolumn{1}{c}{$\Delta M$} & \multicolumn{1}{c}{$p$} \\
\hline Control & $9.09(79.69)$ & - & - & $5.74(15.45)$ & - & - \\
$C$ & $6.29(21.99)$ & -2.80 & 0.196 & $33.91(17.28)$ & +28.17 & 0.182 \\
TWL & $-34.97(26.78)$ & -44.06 & 0.516 & $2.91(43.64)$ & -2.83 & 0.893 \\
PWL & $-0.21(30.44)$ & -9.30 & 0.891 & $-37.71(57.47)$ & 43.45 & 0.040 \\
C + TWL & $0.24(10.48)$ & -8.85 & 0.896 & $15.94(31.88)$ & +10.20 & 0.628 \\
C + PWL & $-6.15(25.49)$ & -15.24 & 0.822 & $-36.00(65.89)$ & -41.74 & 0.049 \\
TWL + PWL & $0.71(19.76)$ & -8.38 & 0.902 & $17.67(12.10)$ & +11.93 & 0.571 \\
C + TWL + PWL & $-125.55(73.68)$ & -134.64 & 0.048 & $-43.76(74.51)$ & -49.50 & 0.021
\end{tabular}

Note(s): $M=$ mean; $\mathrm{SD}=$ standard deviation; control refers to the image without warnings, $C=$ claim, $\mathrm{TWL}=$ textual warning label, and $\mathrm{PWL}=$ pictorial Warning Label; $\Delta M=\operatorname{sng}\left(M_{y}-M_{x}\right) d\left(M_{y}, M_{x}\right)$, where $y=$ control, $x=$ other conditions, and $d\left(M_{y}, M_{x}\right)$ is the Euclidean distance

Emotions - Stimulus with low caloric content

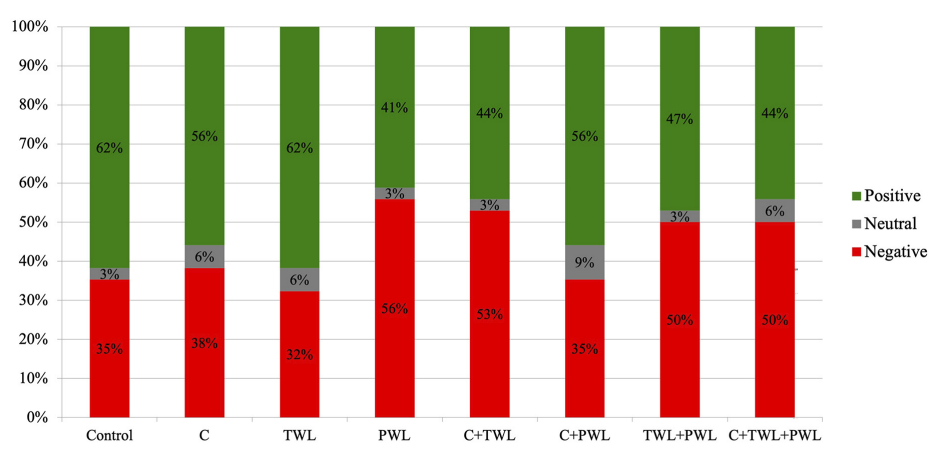

Note(s): Control $=$ the image without warnings; Claim $=\mathrm{C} ;$ Textual warning label $=\mathrm{TWL} ;$ Pictorial Warning Label $=\mathrm{PWL}$

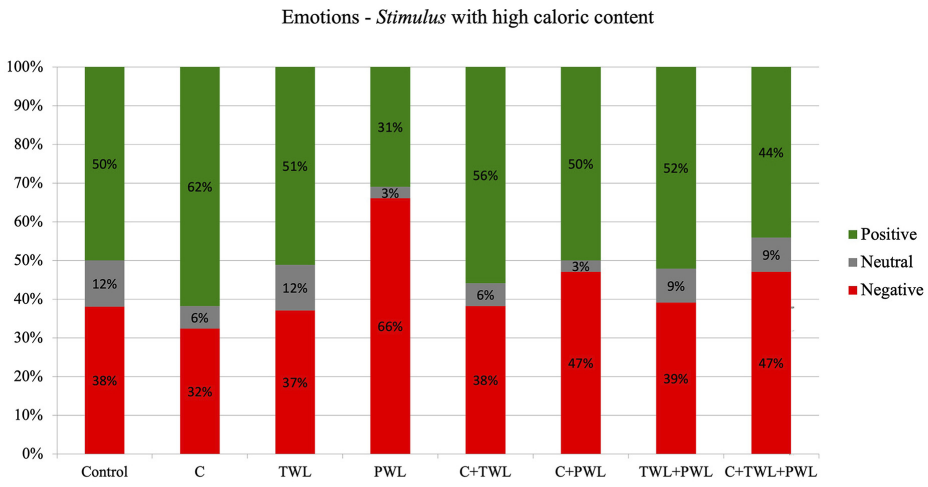

Note(s): Control = image without warnings; Claim $=\mathrm{C}$; Textual warning label $=$ TWL; Pictorial Warning Label $=\mathrm{PWL}$ 
condition with the claim (56\%) or the textual warning label $(62 \%)$ did not change compared to the control condition (62\%). The condition with the pictorial warning label led this proportion to drop to $41 \%$. For the stimulus with high caloric content, negative emotions increase from $38 \%$ in the control condition to $66 \%$ in the condition with the pictorial warning label. Also in this case, the claim (32\%) and the textual warning label (37\%) do not lead to a substantial increase in negative emotions.

\section{General discussion and implications}

This study adds to previous research on the perceived effectiveness of health warning labels and goes further to investigate the effect of three different alcohol warnings on the intention to purchase alcoholic beverages: (1) a responsibility warning statement (claim); (2) a synthetic nutritional table (textual warning label); and (3) an image of a food product with a caloric content similar to the reference beverage (pictorial warning label). Besides, to provide new academic contributions to the existing literature, to the best of authors' knowledge, this is one of the first studies which compares the use of different claims, textual and pictorial warning labels in an alcohol warning context, also testing, through psychophysiological measurements, the impact of negative emotions. Finally, it proposes some specific and useful themes for prevention messages.

First, as for fat consumption (e.g. Argo and White, 2012; Tangari et al., 2019), the findings reveal that both the warning statement (claim) and the textual warning label, displayed for the purpose of preventing alcohol abuse, are ineffective in influencing the intention to purchase an alcoholic beverage. Since less than a third of consumers consider the guideline daily amounts (GDA) while purchasing a product (Wills et al., 2009), these results suggest that they may be tempted to increase consumption due to perceiving the cocktail as a low-calorie drink. Secondly, the outcomes also show that the pictorial warning labels can significantly reduce consumers' purchase intentions. Therefore, pictorial warning labels could help to both contain the "binge drinking" phenomenon and, by providing a better understanding of caloric content, increase consumer awareness of the caloric intake deriving from alcohol consumption, thus reducing the risk of obesity (Barry et al., 2016). In fact, when the pictorial warning labels are displayed, the decrease in purchase intention was greater in the case of the Piña Colada - a cocktail with the caloric content equivalent to an entire hamburger. Considering the brain activation in the left prefrontal region of the cerebral cortex, this study reveals that the pictorial warning labels also trigger negative emotional reactions when participants are exposed to the alcoholic beverage of high caloric content. This outcome is consistent with the occurrence that high threatening pictorial warnings displayed on tobacco packs are the most effective in increasing negative emotions (Droulers et al., 2017).

These findings have theoretical and operational implications. From a theoretical point of view, this research supports similar studies that tested the impact of dissuasive images (Pechey et al., 2020; Wigg and Stafford, 2016) and proposes a new method in the form of pictorial warning labels that could inspire academics and researchers in the food and health disciplines. Indeed, health pictorial warning labels are more valuable than text-only labels in encouraging changes in attitudes, beliefs, and intentions (Gallopel-Morvan et al., 2011; Hammond, 2011). Therefore, to reduce problems of message overexposure (Scott and Solomon, 1998), and to enhance their effectiveness, alcohol warnings must be modified to mitigate weariness.

For policymakers looking at the regulatory aspect, our results suggest that the nutritional values of alcoholic beverages should be reported in both textual and pictorial formats, on both the product label and in advertising. In addition, awareness campaigns might leverage the pictorial content to more effectively inform the public about the risks (e.g. obesity) of excessive alcohol consumption, or even reduce the compulsive consumption of these products 
BFJ 123,13

(Piper et al., 2020). By incorporating these labels, policymakers may be able to reduce the "binge-drinking" phenomenon. Finally, the use of more positive images might garner the support of companies, which often disapprove of government directives, especially when they involve unpleasant images (Crosbie and Glantz, 2014). This would provide opportunities for marketing professionals who work in the food industry to create attractive advertising campaigns in line with policymakers' interests. In this way, appropriate health warnings can have a positive impact on consumers' quality of life, and by extension, on the economy.

Lastly, the present study features some methodological limitations and ideas that can spur new research. First of all, we highlight the absence of nutritional label on cocktails, since these are usually sold in the place of consumption (e.g. a lounge bar) and do not have a package. Therefore, further in-depth research is needed to understand how textual or pictorial information can be communicated in different settings and to different groups of drinkers. Furthermore, the choice of pictorial elements has been made by a panel of marketing experts. This procedure is limited to subjective preferences and considerations and, therefore, may not be enough to produce efficient stimuli. Future research may focus on formulating pictorial warning labels identifying the specific salient characteristics of the warnings that are capable of dissuading consumers. Likewise, future research should examine whether the effects of the pictorial warning labels on purchase intention vary depending on consumers' age and gender. Finally, it would be important to analyse the factors that could moderate the effects of these images on consumer perception and on purchase intentions, such as situational and behavioural factors (time constraints, special diet status) (Annunziata et al., 2016a, b; Grunert et al., 2010), or nutritional knowledge and health awareness.

\section{References}

Ajzen, I. and Fishbein, M. (1980), Understanding Attitudes and Predicting Social Behavior, PrenticeHall, Englewood Cliffs, NJ.

Al-hamdani, M. (2014), "The case for stringent alcohol warning labels: lessons from the tobacco control experience", Journal of Public Health Policy, Vol. 35 No. 1, pp. 65-74.

Al-hamdani, M. and Smith, S. (2015), "Alcohol warning label perceptions: emerging evidence for alcohol policy", Canadian Journal of Public Health, Vol. 106 No. 6, pp. e395-400.

Al-hamdani, M. and Smith, S. (2017a), "Alcohol health-warning labels: promises and challenges", Journal of Public Health, Vol. 39 No. 1, pp. 3-5.

Al-hamdani, M. and Smith, S. (2017b), "Alcohol warning label perceptions: do warning sizes and plain packaging matter?", Journal of Public Health Policy, Vol. 78 No. 1, pp. 79-87.

Allman, J.M., Hakeem, A., Erwin, J.M., Nimchinsky, E. and Hof, P. (2001), "The anterior cingulate cortex. The evolution of an interface between emotion and cognition", Annals of the New York Academy of Sciences, Vol. 935 No. 1, pp. 107-117.

Andersson, C., Sundh, V., Waern, M., Jakobsson, A., Lissner, L. and Spak, F. (2013), "Drinking context and problematic alcohol consumption in young Swedish women", Addiction Research and Theory, Vol. 21 No. 6, pp. 457-468.

Annunziata, A., Pomarici, E., Vecchio, R. and Mariani, A. (2016a), "Do consumers want more nutritional and health information on wine labels? Insights from the EU and USA", Nutrients, Vol. 8 No. 7, p. e416.

Annunziata, A., Pomarici, E., Vecchio, R. and Mariani, A. (2016b), "Nutritional information and health warnings on wine labels: exploring consumer interest and preferences", Appetite, Vol. 106, pp. 58-69.

Argo, J.J. and White, K. (2012), "When do consumers eat more? The role of appearance self-esteem and food packaging cues", Journal of Marketing, Vol. 76 No. 2, pp. 67-80. 
Barry, A.E., Whiteman, S.D. and Cremeens-Matthews, J. (2016), "Alcohol-attributable calories consumed as a result of binge drinking: a national survey of drinkers in the United States", Substance Use and Misuse, Vol. 51 No. 7, pp. 932-936.

Bartoli, F., Carretta, D., Crocamo, C., Schivalocchi, A., Brambilla, G., Clerici, M. and Carrà, G. (2014), "Prevalence and correlates of binge drinking among young adults using alcohol: a crosssectional survey", BioMed Research International, Vol. 2014, pp. 1-7.

Battista, K. and Letherdale, S. (2017), "Estimating how extra calories from alcohol consumption are likely an overlooked contributor to youth obesity", Health Promotion and Chronic Disease Prevention in Canada, Vol. 37 No. 6, pp. 1-18.

Bayliss, L. and Krieger, J. (2018), "Calories in context: conceptual metaphors and consumers' perception and use of calorie information", Journal of Health Communication, Vol. 23 No. 8, pp. 1-8.

Berčík, J., Horská, E., Wang, W.Y.R. and Chen, Y.C. (2015), "How can food retailing benefit from neuromarketing research: a case of various parameters of store illumination and consumer response", 143rd Joint EAAE/AAEA Seminar, 25-27 March 2015, Naples, European Association of Agricultural Economists.

BEUC (2015), The European Consumers' Organization, “Report on European Consumers' Perception of Foodstuffs Labelling”, BEUC/X/032/2005, Bureau Européen des Unions de Consommateurs, Bruxelles.

Borland, R., Wilson, N., Fong, G., Hammond, D., Cummings, K., Yong, H., Hosking, G., Thrasher, H. and McNeill, A. (2009), "Impact of graphic and text warnings on cigarette packs: findings from four countries over five years", Tobacco Control, Vol. 18 No. 5, pp. 358-364.

Brewer, N., Hall, M., Noar, S., Parada, H., Stein-Seroussi, A., Bach, L., Hanley, S. and Ribisl, K. (2016), "Effect of pictorial cigarette pack warnings on changes in smoking behavior: a randomized clinical trial", JAMA International Medicine, Vol. 176 No. 7, pp. 905-912.

Bui, M., Burton, S., Howlett, E. and Kozup, J. (2008), "What am I drinking? The effects of serving facts information on alcohol beverage containers", The Journal of Consumer Affairs, Vol. 42 No. 1, pp. 81-99.

Bush, G., Luu, P. and Posner, M.I. (2000), "Cognitive and emotional influences in anterior cingulate cortex”, Trends in Cognitive Sciences, Vol. 4 No. 6, pp. 215-222.

Cacioppo, J.T., Tassinary, L.G. and Berntson, G.G. (2016), Handbook of Psychophysiology, 4th ed., Cambridge University Press, Cambridge, available at: https:/www.cambridge.org/core/books/ handbook-of-psychophysiology/EACAC4007D68C77D20B912D18C78A370.

Campos, S., Doxey, J. and Hammod, D. (2011), "Nutrition labels on pre-packaged foods: a systematic review", Public Health Nutrition, Vol. 14 No. 8, pp. 1496-1506.

Carrillo, E., Fiszman, S., Lähteenmäki, L. and Varela, P. (2014), “Consumers' perception of symbols and health claims as health-related label messages. A cross-cultural study", Food Research International, Vol. 62, pp. 653-661.

Carroll, T., Stewart, C., King, E. and Taylor, K. (2005), "Research report: consistency of alcohol advertising and promotion on the Internet with the revised alcohol beverage advertising code", available at: http://www.alcohol.gov.au/internet/alcohol/publishing.nsf/content/ 963e09ffe16aef1ece2571e3001f0edd/file/consistent-internet.pdf (accessed 12 December 2019).

Chakraborty, S. (2014), "Analysis of NHANES 1999-2002 data reveals noteworthy association of alcohol consumption with obesity", Annals of Gastroenterology, Vol. 27, pp. 250-257.

Chandon, P. and Wansink, B. (2007a), "Is obesity caused by calorie underestimation? A psychophysical model of meal size estimation”, Journal of Marketing Research, Vol. 44 No. 1, pp. 84-99.

Chandon, P. and Wansink, B. (2007b), "The biasing health halos of fast-food restaurant health claims: lower calorie estimates and higher side-dish consumption intentions", Journal of Consumer Research, Vol. 34 No. 3, pp. 301-314. 
BFJ 123,13

Cowburn, G. and Stockley, L. (2004), "Consumer understanding and use of nutrition labelling: a systematic review", Public Health Nutrition, Vol. 8 No. 1, pp. 21-28.

Craig, J., Netemeyer, R. and Durvasula, S. (1993), "The role of cognitive responses as mediators of alcohol warning label effects", Journal of Public Policy and Marketing, Vol. 12 No. 1, pp. 57-68.

Crosbie, E. and Glantz, S. (2014), "Tobacco industry argues domestic trademark laws and international treaties preclude cigarette health warning labels, despite consistent legal advice that the argument is invalid", Tobacco Control, Vol. 23 No. 3, pp. 1-21.

D'Alessio, M., Baiocco, R. and Laghi, F. (2006), "The problem of binge drinking among Italian university students: a preliminary investigation”, Addictive Behaviors, Vol. 31, pp. 2328-2333.

De Salvia, M.A., D’Uggento, A.M., Aquilino, G., Tattoli, M., Finelli, C., Imbrici, P., Desaphy, J.F. and Giustino, A. (2019), "Characterization of student drinking behaviors at the beginning of the first academic year at one university in southern Italy", Journal of Addictions Nursing, Vol. 30 No. 3, pp. 193-200.

Di Grande, L., Perrier, M.P., Lauro, M.G. and Contu, P. (2000), "Alcohol use and correlates of binge drinking among university students on the Island of Sardinia”, Italy. Substance Use and Misuse, Vol. 35 No. 10, pp. 1471-1483.

Droulers, O., Gallopel-Morvan, K., Lacoste-Badie, S. and Lajante, M. (2017), "The influence of threatening visual warnings on tobacco packaging: measuring the impact of threat level, image size, and type of pack through psychophysiological and self-report methods", PLoS One, Vol. 12 No. 9, e0184415.

Duncan, D.B. (1965), “A Bayesan approach to multiple comparison”, Technometrics, Vol. 7 No. 2 , pp. 171-222.

Etkin, A., Egner, T. and Kalisch, R. (2011), "Emotional processing in anterior cingulate and medial prefrontal cortex", Trends in Cognitive Sciences, Vol. 15 No. 2, pp. 85-93.

EUROCARE (2018), "What's in this drink? Eurocare's position on ingredients and nutritional information”, European Alcohol Policy Alliance, available at: https://www.eurocare.org/media/ GENERAL/docs/reports/2018whatisinthisdrinkeurocarepositiononingredientsandnutritional information.pdf (accessed 20 January 2021).

European Union (2011), "Regulation (EU)1169/2011 of the European parliament and of the council of 25 October 2011", Official Journal of the European Union, Vol. 304, pp. 18-63.

Farace, B., Apicella, A. and Tarabella, A. (2020), "The sustainability in alcohol consumption: the "drink responsibly' frontier”, British Food Journal, Vol. 122 No. 5, pp. 1593-1610.

Gallopel-Morvan, K., Gabriel, P., Le Gall-Ely, M., Rieunier, S. and Urien, B. (2011), “The use of visual warnings in social marketing: the case of tobacco", Journal of Business Research, Vol. 64, pp. 7-11.

Gorski Findling, M., Werth, P., Musicus, A., Bragg, M., Graham, D., Elbel, B. and Roberto, A. (2018), 'Comparing five front-of-pack nutrition labels' influence on consumers' perceptions and purchase intentions", Preventive Medicine, Vol. 106, pp. 114-121.

Grunert, K., Wills, J. and Fernandez-Celemin, L. (2010), "Nutrition knowledge, and use and understanding of nutrition information on food labels among consumers in the UK", Appetite, Vol. 55 No. 2, pp. 177-189.

Guido, G. (2001), The Salience of Marketing Stimuli: an Incongruity-Salience Hypothesis on Consumer Awareness, Kluwer Academic Publisher, Boston, Massachusetts.

Guido, G., Piper, L., Prete, M.I., Mileti, A. and Trisolini, C.M. (2017), "Effects of blue lighting in ambient and mobile settings on the intention to buy hedonic and utilitarian products", Psychology and Marketing, Vol. 34 No. 2, pp. 215-226.

Guzel Aydin, S., Kaya, T. and Guler, H. (2016), "Wavelet-based study of valence-arousal model of emotions on EEG signals with LabVIEW”, Brain Informatics, Vol. 3 No. 2, pp. 109-117. 
Hammond, D. (2011), "Health warning messages on tobacco products: a review", Tobacco Control, Vol. 20 No. 5, pp. 327-337.

Hersey, J., Wohlgenant, K., Arsenault, J., Kosa, K. and Muth, M. (2013), "Effects of front-of-package and shelf nutrition labeling systems on consumers", Nutrition Reviews, Vol. 71 No. 1, pp. 1-14.

IARD (2016), "International alliance for responsible drinking, "health warning labelling requirements", available at: http://www.iard.org/Policy/Policy-Resources/Policy-Tables-by-Country/HealthWarning-Labeling Requirements (accessed 20 January 2021).

ISTAT (2020), "Il consumo di alcol in Italia", available at: https://www.istat.it/it/archivio/244222 (accessed 20 May 2021).

Italian Ministry of Health (2019), "Relazione del Ministro della Salute al Parlamento sugli interventi realizzati ai sensi della Legge 30.3.2001 n. 125 'Legge quadro in materia di alcol e problemi alcol correlati”, available at: https://www.salute.gov.it/portale/documentazione/p6_2_2_1.jsp? lingua $=$ italiano\&id $=2984$ (accessed 8 July 2021).

Jasper, H.H. (1958), "The ten-twenty electrode system of the International Federation", Electroencephalography and Clinical Neurophysiology, Vol. 10, pp. 371-375.

Kanny, D., Naimi, T.S., Liu, Y. and Brewer, R.D. (2020), "Trends in total binge drinks per adult who reported binge drinking - United States, 2011-2017”, Morbidity and Mortality Weekly Report, US Department of Health and Human Services/Centers for Disease Control and Prevention, Vol. 69 No. 2, pp. 30-34.

Kim, H., House, L., Rampersaud, G. and Gao, Z. (2012), "Front-of-package nutritional labels and consumer beverage perceptions", Applied Economic Perspectives and Policy, Vol. 34 No. 4, pp. 599-614.

Kim, B.Y., Nam, H., Yoo, J.J., Cho, Y.Y., Choi, D.H., Jung, C.H., Mok, J.H. and Kim, C.H. (2021), "Association between alcohol consumption status and obesity-related comorbidities in men: data from the 2016 Korean community health survey”, BMC Public Health, Vol. 21, p. 733.

Kuntsche, E., Rehm, J. and Gmel, G. (2004), "Characteristics of binge drinkers in Europe”, Social Science and Medicine, Vol. 59 No. 1, pp. 113-127.

Lahti-Koski, M., Pietinen, P., Heliövaara, M. and Vartiainen, E. (2002), "Associations of body mass index and obesity with physical activity, food choices, alcohol intake, and smoking in the 19821997 FINRISK studies", American Journal of Clinical Nutrition, Vol. 75, pp. 809-817.

Naimi, T.S., Brewer, R.D., Mokdad, A., Denny, C., Serdula, M.K. and Marks, J.S. (2003), "Binge drinking among US adults", Journal of the American Medical Association, Vol. 289 No. 1, pp. 70-75.

National Institute of Alcohol Abuse and Alcoholism [NIAAA] (2021), Binge Drinking, NIAAA, available at: https:/www.niaaa.nih.gov/publications/brochures-and-fact-sheets/binge-drinking (accessed 12 May 2021).

National Institutes of Health - U.S. Department of Health and Human Services (2020), "Rethinking drinking. Alcohol and your health", available at: https://www.rethinkingdrinking.niaaa.nih.gov/ (accessed 24 April 2021).

Newman, C., Burton, S. and Netermeyer, R. (2018), "Marketers' use of alternative front-of-package nutrition symbols: an examination of effects on product evaluations", Journal of the Academy of Marketing Science, Vol. 46 No. 3, pp. 453-476.

Nieuwenhuis, S., Ridderinkhof, K.R., Blom, J., Band, G.P. and Kok, A. (2001), "Error-related brain potentials are differentially related to awareness of response errors: evidence from an antisaccade task", Psychophysiology, Vol. 38 No. 5, pp. 752-760.

Pechey, E., Clarke, N., Mantzari, E., Blackwell, A., De-Loyde, K., Morris, R., Marteau, T. and Hollands, G. (2020), "Image-and-text health warning labels on alcohol and food: potential effectiveness and acceptability", BMC Public Health, Vol. 20, p. 376.

Petrantonakis, P. and Hadjileontiadis, L. (2011), "A novel emotion elicitation index using frontal brain asymmetry for enhanced EEG-based emotion recognition”, IEEE Transactions on Information Technology in Biomedicine, Vol. 15 No. 5, pp. 737-746. 
$\mathrm{BFJ}$ 123,13

Pettigrew, S., Jongenelis, M., Chikritzhs, T., Slevin, T., Pratt, I.S., Glance, D. and Liang, W. (2014), "Developing cancer warning statements for alcoholic beverages", BMC Public Health, Vol. 14 No. 1, pp. 786-791.

Piper, L., Sestino, A. and Guido, G. (2020), "Gluttony as predictor of compulsive buying behavior", British Food Journal, Vol. 123 No. 4, pp. 1345-1361.

Plant, M.A., Plant, M.L., Miller, P., Gmel, G. and Kuntsche, S. (2009), "The social consequences of binge drinking: a comparison of young adults in six European countries", Journal of Addictive Diseases, Vol. 28 No. 4, pp. 294-308.

Podsakoff, P.M., MacKenzie, S.B., Lee, J.Y. and Podsakoff, N.P. (2003), "Common method biases in behavioral research: a critical review of the literature and recommended remedies", Journal of Applied Psychology, Vol. 88 No. 5, pp. 879-903.

Posner, M.I. and Di Girolamo, G.J. (1998), "Executive attention: conflict, target detection, and cognitive control”, in Parasuraman, R. (Ed.), The Attentive Brain, MIT Press, Cambridge, Massachusetts.

Romer, D., Ferguson, S., Strasser, A., Evans, A., Tompkins, M., Macisco, J., Fardal, M., Tusler, M. and Peters, L. (2018), "Effects of pictorial warning labels for cigarettes and quit-efficacy on emotional responses, smoking satisfaction, and cigarette consumption", Annals of Behavioral Medicine, Vol. 52 No. 1, pp. 53-64.

Rosenblatt, D., Dixon, H., Bode, S. and Wakefield, M. (2019), "Evaluating the influence of message framing and graphic imagery on perceptions of food product health warnings", Food Quality and Preference, Vol. 7, pp. 32-42.

Ryan, R.M. and Deci, E.L. (2000), "Intrinsic and extrinsic motivations: classic definitions and new directions", Contemporary Educational Psychology, Vol. 25 No. 1, pp. 54-67.

Salerno, A. and Sevilla, J. (2019), "Scarce foods are perceived as having more calories", available at: https://onlinelibrary.wiley.com/doi/abs/10.1002/jcpy.1090 (accessed 12 April 2020).

ScholesBalog, K.E., Heerde, J.A. and Hemphill, S.A. (2012), "Alcohol warning labels: unlikely to affect alcohol related beliefs and behaviours in adolescents", Australian and New Zealand Journal of Public Health, Vol. 36 No. 6, pp. 524-529.

Scott, D.R. and Solomon, D. (1998), "What is wear out anyway?", Journal of Advertising Research, Vol. 38 No. 5 , pp. 285-330.

Sillero-Rejon, C., Attwood, A., Blackwell, A., Ibáñez-Zapata, J., Munafò, M. and Maynard, O. (2018), "Alcohol pictorial health warning labels: the impact of self-affirmation and health warning severity”, BMB Public Health, Vol. 18 No. 1, pp. 1-9.

Slutske, W.S. (2005), "Alcohol use disorders among US college students and their non-collegeattending peers", Archives of General Psychiatry, Vol. 62 No. 3, pp. 321-327.

Smith, K.C., Cukier, S. and Jernigan, D.H. (2014), "Defining strategies for promoting product through 'drink responsibly' messages in magazine ads for beer, spirits and alcopops”, Drug and Alcohol Dependence, Vol. 142, pp. 168-173.

Stockwell, T. (2006), A Review of Research into the Impacts of Alcohol Warning Labels on Attitudes and Behavior, Centre for Addiction Research of BC University of Victoria British Columbia, available at: https://dspace.library.uvic.ca/bitstream/handle/1828/4785/Alcohol\%20Warning\% 20Labels\%202006.pdf? (accessed 12 February 2021).

Suter, P.M., Hasler, E. and Wilhelm Vetter, W. (1997), "Effects of alcohol on energy metabolism and body weight regulation: is alcohol a risk factor for obesity?", Nutrition Reviews, Vol. 55 No. 5, pp. 157-171.

Talukdar, D. and Lindsey, C. (2013), “To buy or not to buy: consumers' demand response patterns for healthy versus unhealthy food", Journal of Marketing, Vol. 77 No. 2, pp. 124-138.

Tangari, A.H., Bui, M., Haws, K.L. and Liu, P.J. (2019), "That's not so bad, I'll eat more! Backfire effects of calories-per-serving information on snack consumption”, Journal of Marketing, Vol. 83 No. 1, pp. 133-150. 
Thompson, E.B., Heley, F., Oster-Aaland, F., Stastny, S.N. and Crawford, E.C. (2013), "The impact of a student-driven social marketing campaign on college student alcohol-related beliefs and behaviors", Social Marketing Quarterly, Vol. 19 No. 1, pp. 52-64.

Thomsen, S.R. and Fulton, K. (2007), “Adolescents' attention to responsibility messages in magazine alcohol advertisements: an eye-tracking approach", Journal of Adolescent Health, Vol. 41 No. 1, pp. 27-34.

Traversy, G. and Chaput, J.-P. (2015), "Alcohol consumption and obesity: an update”, Current Obesity Reports, Vol. 4 No. 1, pp. 122-130.

US Institute of Medicine (2005), "Preventing childhood obesity", available at: https://www.ncbi.nlm. nih.gov/pubmed/22379642 (accessed 12 February 2021).

van Herpen, E. and van Trijp, H. (2011), "Front-of-pack nutrition labels. Their effect on attention and choices when consumers have varying goals and time constraints", Appetite, Vol. 57 No. 1, pp. 148-160.

WHO (2018), "World Health Organization. Global status report on alcohol and health", available at: https://www.who.int/publications-detail/global-status-report-on-alcohol-and-health (accessed 12 January 2021).

Wigg, S. and Stafford, L.D. (2016), "Health warnings on alcoholic beverages: perceptions of the health risks and intentions towards alcohol consumption", PLoS One, Vol. 1 No. 4, e0153027.

Wills, J.M., Grunert, K.G., Celemin, L.F. and Bonsmann, S.S. (2009), "Do European consumers use nutrition labels?", AgroFood Industry Hi-Tech, Vol. 20 No. 5, pp. 56-68.

World Population Review (2020), available at: http://worldpopulationreview.com/countries/alcoholconsumption-by-country/ (accessed 12 January 2021).

Yeomans, M.R. (2010), "Alcohol, appetite and energy balance: is alcohol intake a risk factor for obesity?”, Physiology and Behavior, Vol. 100, pp. 82-89.

Young, A.M., Morales, M., McCabe, S.E., Boyd, C.J. and D’Arcy, H. (2005), "Drinking like a guy: frequent binge drinking among undergraduate women", Substance Use and Misuse, Vol. 40 No. 2, pp. 241-267.

\section{Corresponding author}

Luigi Piper can be contacted at: luigi.piper@unisalento.it

For instructions on how to order reprints of this article, please visit our website:

www.emeraldgrouppublishing.com/licensing/reprints.htm

Or contact us for further details: permissions@emeraldinsight.com 